\title{
Kurze Hinweise
}

\section{Journées Montaigne}

400 Jahre sind vergangen, seit Montaigne Mülhausen und Basel besucht hat. Die Universitäten dieser Städte haben sich zu Gedenktagen verbunden, am 24. Oktober 1980 in Mülhausen, tags darauf im Basler Kollegienhaus am Petersplatz. Hier sprachen Andreas Staehelin, Marie-Louise Portmann und der bekannte Montaigne-Forscher René Bernoulli.

\section{Musée d'histoire des sciences de Genève}

Frau Dr. Margarida Archinard, tatkräftige Leiterin des wissenschaftshistorischen Museums in Genf, gibt eine neue Schriftenreihe heraus. Im Dezember 1980 erschienen, von ihr verfaßt, die gut bebilderten Hefte «De Luc et la recherche barométrique» (24 S.) und «L'apport genevois à l'hygrométrie» (32 S.).

\section{Association pour le patrimoine industriel}

Marc-Antoine Barblan, Präsident der Gesellschaft für das industrielle Erbgut (Sekretariat im Palais de l'Athénée, rue de l'Athénée, 1205 Genève), hat mit der Sammlung aufschlußreicher Maschinen-Veteranen der Westschweiz begonnen. Eine erste Ausstellung in den Räumen der «Services Industriels de Genève» dauerte von November 1980 bis Februar 1981.

\section{Beförderungen}

Bei unserem Landsmann Nikolaus Mani in Bonn hat sich 1980 die Medizinhistorikerin und Arabistin Frau Dr.phil. Friedrun Roswitha Hau-Müller habilitiert. Ihre Antrittsvorlesung vom 20. Januar 1981 betraf die «Rezeption der griechischen Heilkunst durch die arabische Medizin im Mittelalter».

Prof.Dr.med. Axel Hinrich Murken vom Medizinhistorischen Institut in Münster in Westfalen, der kenntnisreiche Spitalhistoriker und Redaktor der Zeitschrift «Historia hospitalium», hat im November 1980 den Ruf an die Technische Hochschule Aachen erhalten. 